\title{
Peri-urban dynamics and land-use planning for the Greater Cairo Region in Egypt
}

\author{
M. Salem \\ Faculty of Urban and Regional Planning, Cairo University, Egypt
}

\begin{abstract}
Although there is no consensus on the definition of the peri-urban areas, there is growing recognition among development professionals that rural and urban features tend to increasingly co-exist within cities and beyond their limits. This research discusses the peri-urban area through reviewing previous literature. In addition, to define the criteria of delimitation of peri-urban areas in light of those literatures, therefore, delimitation of peri-urban areas of Greater Cairo.

Peri-urban areas of the Greater Cairo Region (GCR) represent $24 \%$ of the region's population. However, there is no urban planning or land management carried out by the government in those areas. Furthermore, these areas are expected to be a part of a metropolitan area of Greater Cairo within a few years, because of urban sprawl of the metropolis and urbanization dynamics in these areas Therefore, peri-urban areas can either make a great contribution to the urban development of the GCR or become a new belt of slums surrounding the region, according to the procedures of dealing with it.

Moreover, this paper aims to examine the key factors of the urbanization process in peri-urban areas of the GCR through correlation analysis between those factors and the urbanization indicators in those areas. In addition, to discuss the appropriate procedures for managing land uses in those areas. The findings of this research confirmed that the percentage of non-agriculture workers, percentage of illiterate, and the existing regional services are the most important factors in the process of the urbanization process in peri-urban areas of the GCR.
\end{abstract}

Keywords: peri-urban area, urbanization process, land use dynamics, metropolitan region, Greater Cairo Region. 


\section{Introduction}

The most recent studies of metropolitan regions have often focused on either metropolitan area or rural hinterlands distant from the metropolis, with little work on the peri-urban areas in the context of metropolitan. In developing countries, a substantial and growing proportion lives in or around metropolitan areas and large cities, including the zone termed the 'peri-urban areas', which is neither solely urban nor rural $[1,2]$.

Recently, many studies give attention to rural urban interface and a lot of attempts to describe these areas However, Thuo [3] noted that a quantifiable criterion that one might utilize to identify the peri-urban into an actual area does not exist. Nevertheless, some agreement over definitions or appropriate terminology to describe the peri-urban area has emerged [4, 5].

The Greater Cairo Region (GCR) in Egypt is considered one of the greatest metropolitan regions in the world with population of 20 million inhabitants (estimated 2014). GCR has attracted considerable scholarly attention. However, all previous planning efforts (Mater plan 1970, long term development plan 1983, first master plan 1991, update of master plan 1997, and strategic plan 2008) did not give peri-urban areas the required attention. Moreover, it didn't care about the sphere of influences of the metropolis [6].

\section{Literature review}

\subsection{Peri-urban areas definitions}

There is growing recognition among professionals and researchers that periurban areas tend increasingly to co-exist within cities and beyond their limits. Peri-urban areas are considered a transitional zones between the city and the countryside, where urban and rural activities are juxtaposed and the landscape features are subject to rapid transformations induced by human activities [7]. However, definition and attributes of the peri-urban areas are not constant but change according to time and place [5].

There are a lot of terminologies are used by scholars to describe the zone of peri-urban, for example Pryor [8] used the term "rural-urban fringe", Kombe [9] used the term "peri-urban areas", Simon [10] used the term "peri-urban fringe", McGee [11] used the term "desakota regions", and [7] used the term "peri-urban interface", while Bryant et al. [12] used the term "Urban Shadow" to describe the end of this zone.

As a result of this multitude of terms, Thuo [3] mentioned that, confusion in terminology resulting from various studies is considerable, and argued that differentiations may be a result of entrenched ideologies regarding the nature and processes of urban growth. Furthermore, Salem [6] mentioned that, while definitions of peri-urban areas should ideally be based on parameters that are unique to different areas and that are likely to remain constant over time, this is impossible due to peri-urban dynamics. 
Mbiba and Huchzermeyer [13] also observed that there is no spatial definition of the peri-urban area across the world. As such any definition would have to be specific to some interests with precise criteria. Thuo [3] argued, therefore, that the definition of peri-urban zone thus need to be developed depending on specific places while identifying several key variables for which threshold values could be categorized.

\subsection{Peri-urban areas in developing countries}

Urbanization in developing countries has generally been more rapid and chaotic than in developed countries with deficiencies in regulation and infrastructural development and the most of the growth was directed to peri-urban areas [14].

The peri-urban areas in developing countries are so different from developed countries, For example, while the experience of developing countries indicates that most of those occupying this area are engaged in informal economic activities $[15,16]$, while those in developed countries, are mostly from upper and middle income groups [17]. Furthermore, there are differentiations in structure of land uses, migration reasons and Development approaches.

Although Peri-urban areas in developing countries may show some common characteristics, there are some differences as well. Differences are a result of historical, legal, cultural and social backgrounds of different countries and regions within each country [3].

\subsection{Land use dynamics in peri-urban areas}

Land use changes of peri-urban areas are a dynamic process, which involves both natural and human systems. These changes in Land uses of the peri-urban areas are followed by transformation of peri-urban areas' structure from agricultural to industrial and residential [16].

In an attempt to show why there is an uneven land use development in periurban areas, Bryant et al. [12] noted that urban development may not occur around all urban centres in all directions, due to variations in societal response to changes within the surrounding areas of a particular city. This makes the periurban areas a discontinuous spatial phenomenon in metropolitan regions.

Masuda and Garvin [4] indicated that there are many forces that affect land uses in peri-urban areas and stated social, economic, political and cultural forces as main factors. Moreover, they included housing and land markets, planning decisions, ownership patterns, land use characteristics, infrastructure and transportation structure and roles of actors within these processes.

Maconachie [14] indicated that in managing land uses, different governments have come up with a range of public policies and regulations. These regulations constrain landholders' options for the use of land, and thus influence present and future market values of land. Government policies that promote infrastructural development may also influence the use of land. Furthermore, policies such as those related to land rates and taxes influence landholders' financial calculations and therefore influence the way they use land [14]. 
In developing regions, peri-urbanization is partly fuelled by land speculation. As speculators hold on to parcels around the city, new developments occur in a haphazard manner, often pushed to locations farther away from the central city creating a pattern of scattered development. Furthermore, urban dwellers moving to the peri-urban area to take advantage of low land rents or to capitalize on new opportunities for land acquisition, speculation and informal enterprise [18].

\section{Methodology}

The research depended on qualitative and quantitative methodology. First, the research used the qualitative method for defining peri-urban areas of GCR. Secondly, the research depended on quantitative method for defining key factors of urbanization process in peri-urban areas, through correlation analysis.

The data sources were from Central Agency for Public Mobilization and Statistics (CAPMAS) and human development report. The data were analyzed by SPSS and Excel programs.

\subsection{Defining peri-urban areas of the Greater Cairo Region}

The study area was the peri-urban areas of GCR in Egypt, which were situated in range between 15 and $40 \mathrm{~km}$ from urban core of GCR. The research depended on the result of literatures review and empirical studies to define the peri-urban areas of GCR.

A literature review and empirical studies showed some criteria for delimitation of peri-urban areas in developing countries [5, 6, 15, 19]. Those criteria were as following: the proportion of agricultural land use to urban land use was about four to one, Low densities in comparison with other parts with metropolitan region (300-1000 person/hectare), urban activities is increasing rapidly, starting to illegal agricultural land subdivision, the percentage of nonagriculture workers $(20-40 \%)$. In addition, the range of spatial definitions were from 20-50 beyond the urban core and may have reached up to $150 \mathrm{~km}$ in parts of East Asia and China [20].

The peri-urban areas of GCR were defined according to previous criteria, hence those areas were situated in range from $15 \mathrm{~km}$ to $40 \mathrm{~km}$ away from urban core and it were consisted of more than 70 villages and small towns. Moreover, peri-urban areas of GCR represented $24 \%$ of region's population (approximately 4 million persons) (see table 1).

Table 1: Peri-urban areas share of Greater Cairo's population.

\begin{tabular}{|l|c|c|c|c|c|}
\hline $\begin{array}{l}\text { Greater Cairo } \\
\text { Region }\end{array}$ & $\begin{array}{c}1996 \\
\text { population }\end{array}$ & $\begin{array}{c}2006 \\
\text { population }\end{array}$ & $\begin{array}{c}\text { Annual } \\
\text { increase (\%) }\end{array}$ & $\begin{array}{c}\text { Absolute } \\
\text { increase }\end{array}$ & $\begin{array}{c}\text { Share of absolute } \\
\text { increase (\%) }\end{array}$ \\
\hline Core agglomeration & 10188333 & 11748240 & 1.43 & 1517102 & 50.3 \\
\hline Peri-urban areas & 2857468 & 3942262 & 3.27 & 1084794 & 35.9 \\
\hline New towns & 184695 & 601767 & 12.54 & 417072 & 13.8 \\
\hline Total GC & 13230496 & 16292269 & 2.1 & 3018968 & 100 \\
\hline
\end{tabular}


The size of settlements in peri-urban areas were varies greatly, from small villages with populations of less than 5000 persons to huge agglomerations of more than 100,000 persons. The rate of population growth in those areas was reached to $3.3 \%$ between 1996 and 2006, which was higher than average rates of other parts in GCR.

\section{Results}

\subsection{Peri-urban growth and land use dynamics}

The last few decades witnessed high growth rates of urban lands in GCR, which increased from 34,440 ha in 1986 to 40,900 ha in 2001 [21], until they reached 436,500 ha in 2007 (see fig. 2). The majority of these increases in urban lands came from the conversion of farmland in peri-urban areas, at a rate that reached up to $300-600 \mathrm{ha} / \mathrm{year}$. Therefore, the period of 2000 is considered the era of the emergence of peri-urban areas in GCR (see fig. 2).

The total transformations of lands towards urban uses in peri-urban areas was 37,000 ha and most of those lands (2300 ha) were agriculture lands. However, the total transformations of lands towards urban uses for main agglomeration was 5700 ha, which was as following 1100 ha from agriculture lands, 3400 from desert lands and 1200 ha from other land uses (see fig. 1).

It is noticeable that the pattern of urbanization for peri-urban areas, just like scattered urban islands (leap frog pattern) and more visible along or near major roads and railways

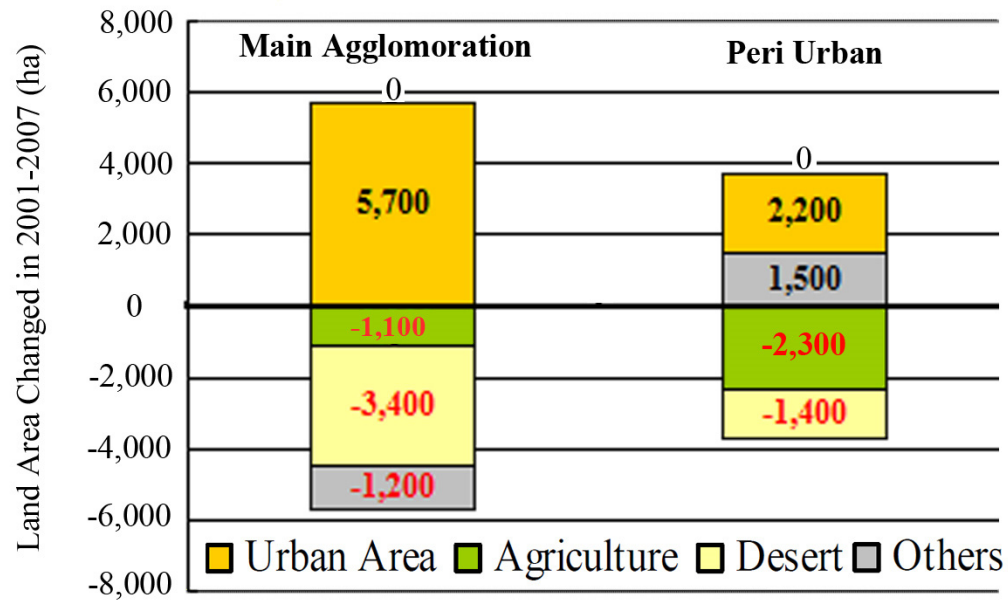

2007

2001

Figure 1: Transformations of land uses for peri-urban areas in GCR. 


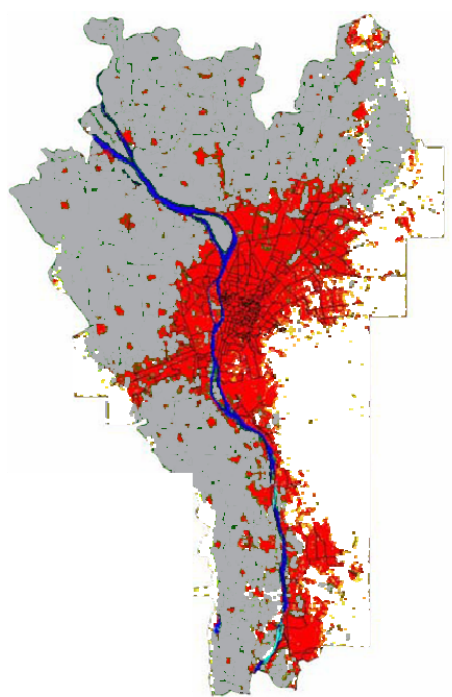

1986

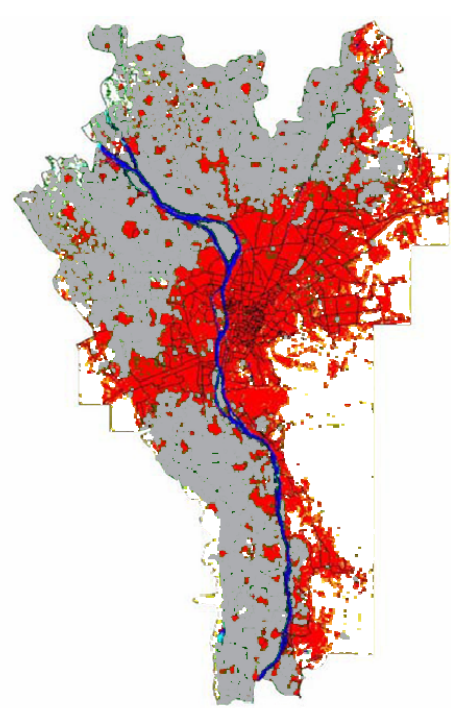

2001

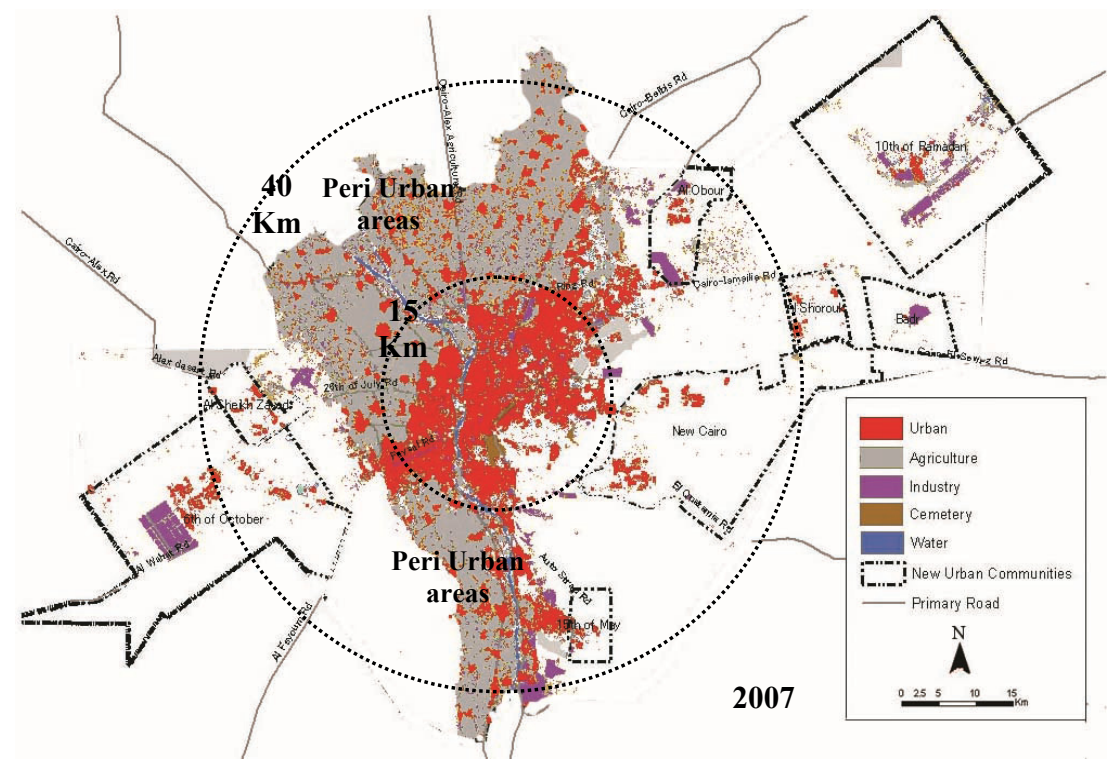

Figure 2: The emergence of peri-urban areas in GCR. Source: adaptation from JICA study.

\subsection{Driving forces of urbanization in peri-urban areas}

Several forces are responsible for urbanization in peri-urban areas, which are discussed in the following section. 


\subsubsection{Percentage of non-agriculture workers}

Although officially the peri-urban areas of Greater Cairo are classified as rural, over the last few decades the role of agriculture has diminished significantly, which reflected on percentage of non-agriculture workers. The result of the correlation coefficient between urbanization indicators for peri-urban areas and the percentage of non-agriculture workers was $>0.6$, which signifies a strong positive correlation.

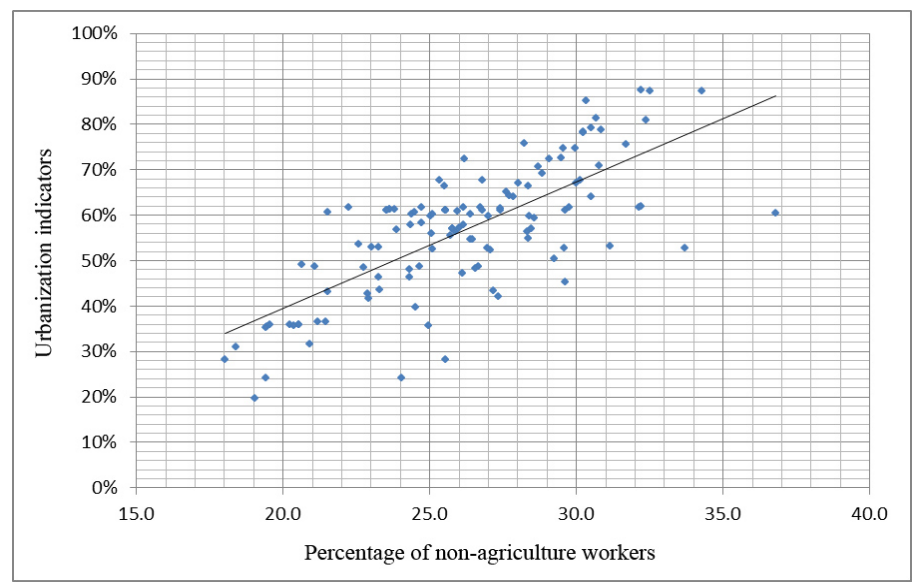

Figure 3: Correlation coefficient between urbanization indicators and percentage of non-agriculture workers.

\subsubsection{Percentage of illiterates (uneducated)}

The result of correlation coefficient between urbanization indicators for periurban areas and Percentage of illiterates was $>-0.6$, which mean strong negative correlation.

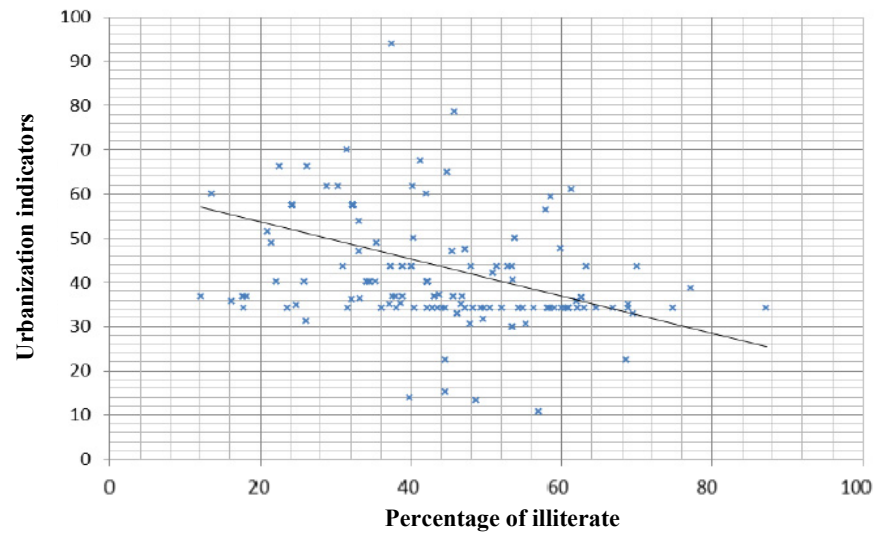

Figure 4: Correlation coefficient between urbanization indicators and percentage of illiterates. 


\subsubsection{Existing of regional services}

The peri-urban area settlements were classified into three categories (Class A, Class B, and Class C) according to the number of regional service units in every settlement. It was clear that there is an increase in urbanization indicators of the high class (class A) category.

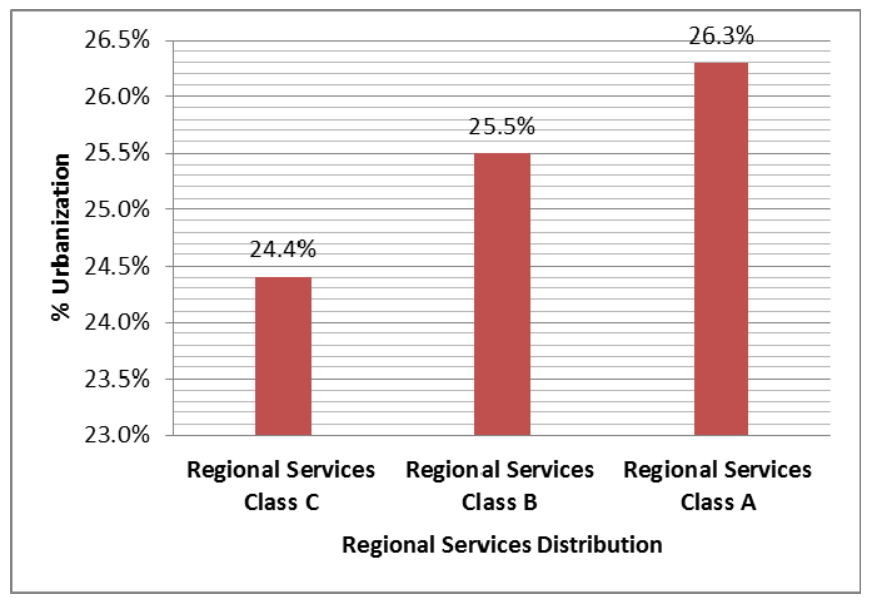

Figure 5: Percentage of urbanization and the distribution of regional services in peri-urban areas.

\subsubsection{Accessibility}

The result of correlation coefficient between urbanization indictors for periurban settlements and the accessibility for these settlements was 0.22 , which indicates a low positive correlation.

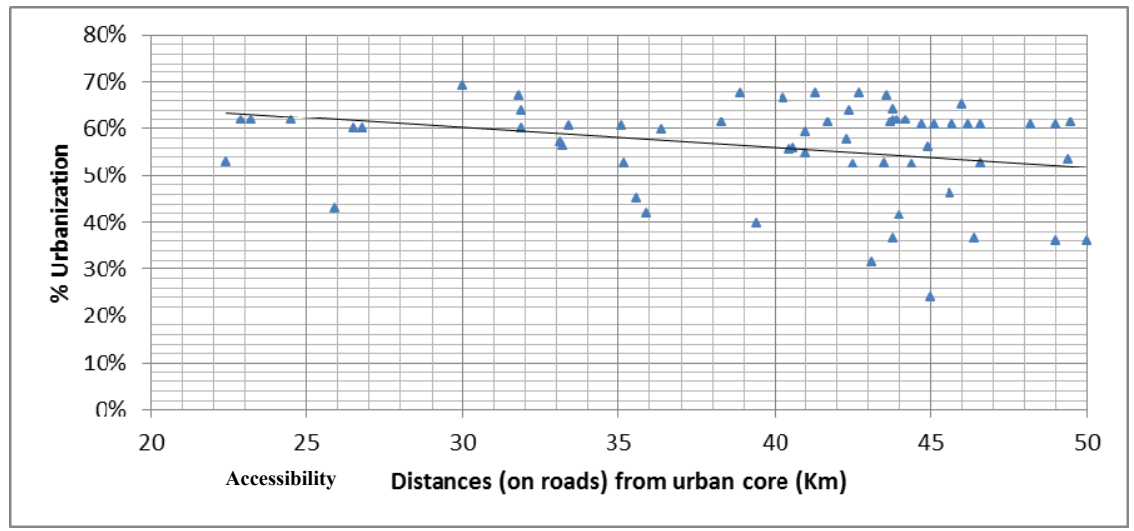

Figure 6: Correlation coefficient between urbanization and the accessibility. Source: author. 


\section{Discussion}

Peri-urban areas in GCR were situated in a range between $15 \mathrm{~km}$ to $40 \mathrm{~km}$ from the urban core of the region. However, this range is valid during the period of the research and can be changed, due to sphere of influence of metropolis and urban dynamics of peri-urban as well.

The correlation coefficient between percentage of urbanization in peri-urban settlements and the accessibility for these settlements was 0.22 , which means a low positive correlation. However, the empirical evidences on maps show that the relation is stronger than this result. The previous result can be interpreted as following: the research depended on measuring the accessibility by the distances between the peri-urban settlements and urban core on roads $(\mathrm{km})$, while it is not accurate enough. Thus, the accessibility should be measured by time to give accurate results. However, it was difficult to be done due to the large number of settlements in peri-urban area of GCR.

The main reason for the growing attraction of peri-urban areas to a vast block of Greater Cairo's population can be due to affordable housing solutions that the mainly informal housing markets generate in these areas. Land accessibility and low price is conducive for informal settlement creep. In addition, there is less control prohibiting building on agricultural land in these settlements than along peripheries of the core agglomeration of Greater Cairo.

Formulating policies of land uses in peri-urban areas required incorporation peri-urban into Greater Cairo strategy, as first step.

The Government of GCR must recognize the urban dynamic of peri-urban areas, and track the rapid population growth of poor and modest income families in those areas; otherwise, it may be transformed to slums as the current peripheries of GCR.

There are certainly many problems peri-urban areas, but they relate mostly to the lack of sufficient state investments in infrastructure and public services to keep up with population growth; therefore, allocation sufficient budget for investments in infrastructure and public services in peri-urban areas could make these areas much better.

The informal process of conversion of agricultural land to urban use is also straightforward. A farmer will commonly divide agricultural strips into several building plots (average size $110 \mathrm{~m}^{2}$ ) or might sell the whole strip to a middleman sub divider. In both instances, he will be paid the market price.

\section{Conclusion}

There are numerous terminologies used by scholars to describe the interface area between urban and rural, and some scholars argued that those terms are solely synonymous; therefore, every researcher in this field should be aware of all those terminologies. On the other hand, this paper concludes that there is no single way to define or delimitate peri-urban areas, because there are no definite boundaries, administratively speaking. However, there are general criteria, which can be used 
as a guide. In other words, precise definition or delimitation should be done according to each case study, with explicit criteria.

According to the literature review, the peri-urban areas' characteristics differ greatly between developing countries and developed countries, particularly in future plans.

The main key factors of peri-urbanization process in GCR are the percentage of non-agriculture workers, percentage of illiterate (uneducated) citizens in the peri-urban settlements and accessibility between those settlements and main agglomeration of GCR.

Rapid population growth for GCR has led to an increasing demand for urban land whether for housing or other various urban uses. Most of that demand was directed towards peri-urban areas, due to high price of lands within metropolitan area. On contrary, the prices of lands in peri-urban areas were affordable.

There is no doubt that land development control plays a pivotal role in driving peri-urban growth. Land speculation emerged as a response to the absence of land-use plan enforcement. Land use policies could be adopted to direct industry and other non-compatible land uses away from valuable rural hinterlands either to peri-urban areas, which are less heavily populated and are less valuable (e.g. swamps and low-lying land, barren soils, etc., especially those in state ownership) or towards desert lands in the east or the west.

There exists the necessity for preparing a strategy for dealing with available lands in peri-urban areas, instead of haphazard development. Spatial planning of peri-urban areas can enhance the ability of those areas to meet the future needs of Greater Cairo's inhabitants, whether for housing or services.

\section{References}

[1] Ford, T., Understanding population growth in the peri-urban region. International Journal of Population Geography, 1999, 5(4): pp. 297-311.

[2] Brook, R.M. and J. Dávila, The Peri-Urban Interface: a Tale of Two Cities. 2000, Gwasg Ffrancon Printers, Bethesda, Gwynedd,Wales: Great Britain.

[3] Thuo, A.D.M., Unsettled Settled Spaces: Searching for a Theoretical 'Home' for Rural-Urban Fringes. International Journal of Scientific and Research Publications, 2013, 3(7).

[4] Masuda, J.R. and T. Garvin, Whose Heartland?: The politics of place in a rural-urban interface. Journal of Rural Studies, 2008, 24(1): pp. 112-123.

[5] Simon, D., D. McGregor, and K. Nsiah-Gyabaah, The changing urbanrural interface of African cities: definitional issues and an application to Kumasi, Ghana. Environment and Urbanization, 2004, 16(2): pp. 235-248.

[6] Salem, M., Urban transformations in the peri-urban interface of metropolitan regions "Case study: Greater Cairo Region”, in Regional Planning department. 2014, Cairo University: Cairo, Egypt.

[7] Allen, A., Environmental planning and management of the peri-urban interface: perspectives on an emerging field. Environment and Urbanization, 2003, 15(1): pp. 135-148. 
[8] Pryor, R.J., Delineating Outer Suburbs and the Urban Fringe. Geografiska Annaler. Series B, Human Geography, 1969, 51(1): pp. 3338 .

[9] Kombe, W.J., Land use dynamics in peri-urban areas and their implications on the urban growth and form: the case of Dar es Salaam, Tanzania. Habitat International, 2005, 29(1): pp. 113-135.

[10] Simon, D., Urban Environments: Issues on the Peri-Urban Fringe. Annual Review of Environment and Resources, 2008, 33(1): pp. 167-185.

[11] McGee, T.G., Emergence of Desakota Regions in Asia: Expanding a hypothesis, in The Extended Metropolis: Settlement Transition Is Asia, B.K. Norton Sydney Ginsburg, T. G. McGee, Editor. 1991, University of Hawaii Press.

[12] Bryant, C.R., L.H. Russwurm, and A.G. McLellan, The city's countryside: land and its management in the rural-urban fringe. 1982: Longman.

[13] Mbiba, B. and M. Huchzermeyer, Contentious development: peri-urban studies in sub-Saharan Africa. Progress in Development Studies, 2002, 2(2): pp. 113-131.

[14] Maconachie, R., Urban Growth and Land Degradation in Developing Cities: Change and Challenges in Kano Nigeria. 2012: Ashgate Publishing, Ltd.

[15] Pradoto, W., Development patterns and socioeconomic transformation in peri-urban area "Case of Yogyakarta, Indonesia". 2012, University of Technology: Berlin.

[16] Oduro, C.Y., Effects of Rapid Urbanization on Livelihoods in the PeriUrban Areas of Accra, Ghana, in Department of Urban and Regional Planning. 2010, Florida State University.

[17] Furuseth, O.J. and M.B. Lapping, Contested countryside : the rural urban fringe in North America. Aldershot; Brookfield, Vt. : Ashgate, 1999.

[18] Briggs, J. and D. Mwamfupe, Peri-urban Development in an Era of Structural Adjustment in Africa: The City of Dar es Salaam, Tanzania. Urban Studies, 2000, 37(4): pp. 797-809.

[19] Handayani, W., Rural-Urban Transition in Central Java: Population and Economic Structural Changes Based on Cluster Analysis. Land, 2013, 2(3): pp. 419-436.

[20] Dutta, V., Land Use Dynamics and Peri-urban Growth Characteristics: Reflections on Master Plan and Urban Suitability from a Sprawling North Indian City. Environment and Urbanization Asia, 2012, 3(2): pp. 277-301.

[21] Yin, Z.-Y., et al., Changes in urban built-up surface and population distribution patterns during 1986-1999: A case study of Cairo, Egypt. Computers, Environment and Urban Systems, 2005, 29(5): pp. 595-616. 